\title{
COVID-19 GROUNDED AIRCRAFT - PARKING AND STORING
}

Francisco Serrano ${ }^{1,2}$, Antonín Kazda ${ }^{1, *}$

${ }^{1}$ University of Zilina, Zilina, Slovakia

${ }^{2}$ Hamad International Airport, Doha, Qatar

*E-mail of corresponding author: antonin.kazda@fpedas.uniza.sk

\section{Resume}

Air transport industry is one the many sectors significantly impacted by the COVID-19 pandemic. Travel restrictions and bans resulted in reduction in aircraft operation. Airlines have no option than to limit their services by grounding their fleet: as of April 2020, out of 22,000 passenger aircraft around the world, almost 14,400 were grounded [1]. Airport operators are trying to accommodate most of the grounded aircraft by utilizing their main operational space as aprons, taxiways and runways. The limited space at airports often means that aircraft have to be parked in non-standard positions, which may affect the airport daily operations. While planning aircraft parking, safety is the top priority. The effect of long-term load was not considered in the pavement design and could result in increased pavement maintenance requirements. Airport operators must also reflect aircraft maintenance needs in terms of engines, hydraulics, braking system, cabin interior and others.

\section{Article info}

Received 9 July 2020

Accepted 6 October 2020

Online 23 February 2021

\section{Keywords:}

aircraft grounding, parking positions, storing aircraft, pavement strength, aircraft maintenance

ISSN 1335-4205 (print version)

ISSN 2585-7878 (online version)

\section{Introduction}

Specifications for the aprons and aircraft stands are globally defined by the International Civil Aviation Organization (ICAO), Annex 14, Volume I, Aerodrome Design and Operations [2]; in the EU by the Regulation (EU) No 139/2014 [3]; or in the USA by the Federal Aviation Administration (FAA) Airport Design and Engineering Standards AC, 150/5300-13, Apron, (Appendix 5) [4]. More details about apron and stand characteristics can be found in the ICAO Aerodrome Design Manual, Part 2, Taxiways, Aprons and Holding Bays [5]. To build an apron and stand a standard documentation for building permit is usually required, which depending on a particular state, could be very time consuming. The unexpected epidemic of COVID19 created an emergency and urgent situation in terms of aircraft parking requirements. Besides the planning and design requirements, there are operational issues, which significantly differ from the normal airport and airline operation.

The non-standard parking positions for the aircraft at an airport becomes an urgent problem for an airport and airlines during this COVID-19 pandemic. There were airports that had to close their critical facilities to accommodate aircraft due to reduced number of services. On 20 March 2020, the FAA issued National Part 139 CertAlert No. 20-02 [6] to provide recommendation for airport operators while handling the Temporary Parking of Overflow Aircraft. This CertAlert also provides a list of considerations for an airport operator when making decision for overflow aircraft parking.

Another FAA document, The Safety Alert for Operators (SAFO) 20005 [7] provides information for pilots and flight operators on the potential effects of parking overflow aircraft in excess of airport capacity. While the FAA CertAlert has also been used by non-US airports (e.g. in Australia), other countries have issued their own guidance, for example France with a 'Flash Info' on the Storage of Aeroplanes. The upcoming Airport Cooperative Research Program (ACRP), a 'toolbox' on enhancing the management of adverse conditions is being developed by the company WSP USA, will feature reference sheet on the temporary parking of overflow aircraft. Finally, the Infrastructure Workgroup of the French-Speaking Airports (UAF\&FA) will be preparing an extensive guidebook on the same matter later this year.

The COVID-19 pandemic led to drastic and unparalleled collapse in air traffic which grounded significant part of the global airline fleet. As mentioned by Le Bris [8], with reference to Airports Council International (ACI) World report, more than $75 \%$ of commercial airports around the world have already plans in place to accommodate overflow parking. It means that airports will turn into active aircraft storage and such active storage at an airport will need to be arranged, coordinated and synchronized between stakeholders to ensure aircraft protection and encourage easy recovery.

This paper provides a summary of comprehensive 
research in the field of non-standard aircraft parking, analyzes the impacts on airport operations and compares the best of the recommendations and guidance related to non-standard overflow parking positions for aircraft at airports during the COVID-19 pandemic.

\section{Research methodology}

In this research, the focus was on the issue of the COVID-19 pandemic impact on civil aviation, specifically on the area of aircraft grounded and the need for aircraft parking, storing and maintenance. The scale of the problem and especially the speed as it arose is not comparable to any other crisis in the civil aviation. When grounding the Boeing 737 Max 8 it was necessary to provide parking for less than 800 aircraft (387 delivered to customers as of March 2019 [9] and approximately 400 produced and stored as of December 2019 [10]) in case of aircraft parking during the COVID-19 pandemic almost 14,400 aircraft had to be parked [1].

The conducted research is a type of an explanatory research. Referring to [11] 'it explains and confirms the behavior or dependencies in the system and tries to explain the patterns in the behavior of the system, its processes and structure; explanation is an attempt to understand the causes of the phenomena, factors and mechanisms that cause them'. The inductive explanation strategy was used in this research. Behaviour of the system was tried to be explained using some of the 'known' principles, setting general rules and recommendations based on specific cases [12]. The problem of induction could be that '...mind often draws conclusions from relatively limited experiences that appear correct but which are actually far from certain' [13]. When using induction, there is often a problem with the results verification. In this case, the results were verified and confirmed by comparing solutions and findings from different cases [12]. Although the history of COVID-19 is relatively short, the historical method was primarily used in our research. Historical method allows to examine particular events or processes that occurred over short spans of time [14]. In this research a large range of available materials, reports, guidelines, standards and recommended practices published by international organizations, state authorities, airlines and airports, were studied. The historical method comprises the techniques and guidelines by which one uses the primary sources and other evidence to research. The historical research can also mean gathering data from situations that have already occurred and performing statistical analysis on this data just as it would be done in a traditional experiment [15].

We also used a monographic method concentrated in our research on one particular case - problem of overflow aircraft parking. This method understands the researched problem as a whole in contrast to typological method that selects just one aspect [15]

\section{Temporary aircraft parking requirements}

As during this pandemic airports became aircraft storage, parking space is currently very limited and additional parking aprons are a critical need. With apron space at maximum capacity the airport must resort to less desirable options such as parking in non-pavement areas and using space designated for temporary parking. In terms of airport operations and traffic requirements, it could be recommended to use all the space at gates and aprons first, before considering taxiways and runways as parking area options. Concrete pavements should be favored for the long term parking, rather than flexible asphalt pavements.

The options include contact and remote gates, remote overnight parking and aircraft de-icing pads, and active taxiways that could be closed to traffic. A parking situation lasting several months should be reviewed regularly. Existing gates should be utilized first. Once all the stands at the gates are occupied, other options might be considered e.g. the densification of parking on ramps and aprons and then taxiways.

At taxiways selected for aircraft storage different sections that will be closed sequentially can be defined. Taxiway lighting should be turned off on the closed sections and the portion of taxiways leading to these sections (e.g. exits from active taxiway). The parking areas should be closed with barricades with red lights installed as at the airfield construction zone. If a taxiway is closed for aircraft parking, US Department of Transportation also mentioned that the deactivation of the taxiway lighting circuits is a good practice to follow [16]. If deactivation is not feasible as other taxiways on the same circuit must remain open it is advised not to remove the lamp-bulb from energized fixtures because an excessive number of isolation transformers with open end can damage the constant current regulators and/or increase the current flow above its normal value. In this case the solution could be to cover the light fitting so that light leakage can be avoided. It is necessary to secure, identify and place any above ground temporary wiring in conduit to prevent electrocution and fire ignition sources.

In order to use any taxiway for aircraft parking, it must be temporarily closed. The US Department of Transportation has published advisory circular [16] for the airport operators to apply specific markings on the ground to maintain safe operations, such as:

- Place cordons outside the safety area of crossing taxiways;

- To place a mark such as X mark at the entrance of closed taxiway so that it visible form the runway (RWY);

- In the case that the airport operator has a plan to close a taxiway for a long term it is a good practice to remove the centreline marking including the one that is leading to the closed section.

Later, in situation that the taxiway will reopen, the airport operator shall repaint the centreline marking. As 


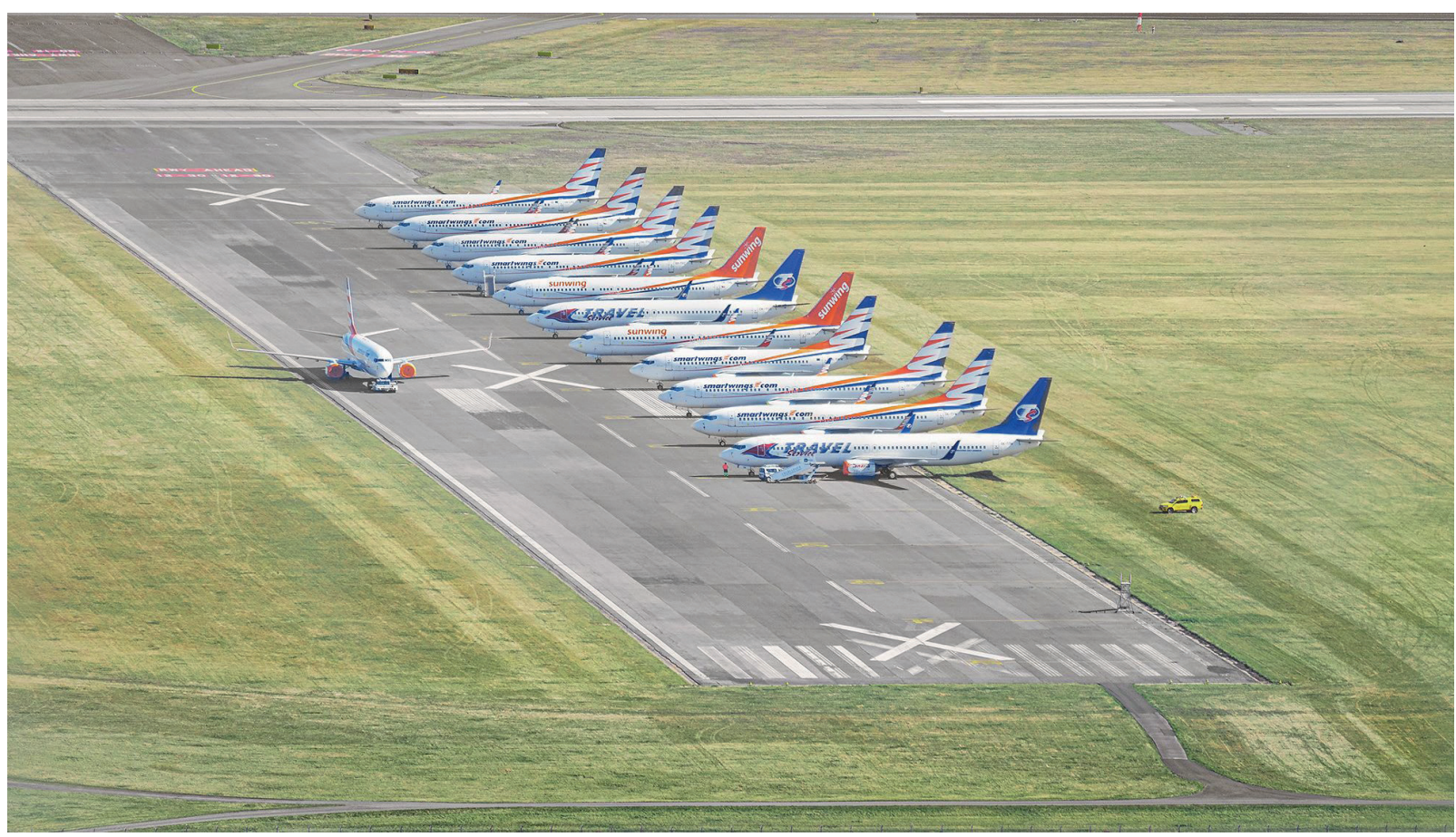

Figure 1 Closed RWY 04/22 at Praha/Ruzyne airport with COVID-19 grounded aircraft parking; marked with 'closed runway marking'; author: Vocelka, T.

already mentioned, the airport operator shall use all the stands at gates and the whole apron as much as they can considering operations safety. If an apron is fully occupied, it must not impede aircraft movement between the stands in operation and the terminal area. However, the airport operator could maximize the use of intermediate taxiway(s) for potential parking.

Runways as temporary parking should be avoided as far as practicable due to the potential of increased safety risk of inadvertent landings on a closed runway. According to FAA guidelines runway closing should become the last option for airport operators due to potential high risk [17]. The FAA took a clear position on this matter in its Part 139 CertAlert on temporary aircraft parking. This is justified by data records of aircraft performing final approaches over temporarily closed runways, some of them with massive obstacles or equipment on the runway that should have alerted pilots or even taxiways occupied by aircraft. However, permanently closed and decommissioned runways can be considered (see Figure 1).

The planning and design of aircraft stands is an important part to support the execution of the new aircraft parking operation. It can be checked and optimized by a full airside exercise before the implementation of the plan. It is also important not only to consider the number and size of stands, but also flows of traffic around the parking area. In order to minimize taxi waiting times and push back interference, different aircraft routing scenarios need to be considered. With the current situation, ACI World published a recommendation for airport operator to develop and update a comprehensive temporary aircraft parking plan [18]. The purpose of a temporary aircraft-parking plan is to identify parking options and priorities and clearly indicate where to park different types of aircraft. The plan should be continuously monitored and updated when required and should identify at least:

- Locations for long, intermediate and short-term parking of aircraft;

- Safety impact of parking options on obstacle limitation surfaces and operations;

- Clearance distances between aircraft;

- Non-standard parking locations that could be used safely for aircraft overflow parking;

- Notification procedures and safety measures when the non-standard parking locations are used (such as runways and taxiways).

Some airports reported using geographic information systems and digital tools to complement the plan and monitor the implementation of changes. Insertion of pictures and diagrams is highly recommended.

For instance, as written by Creedy [19], Brisbane airport expects to have up to 100 aircraft parked ranging from an A380 to QantasLink Dash-08s. The airport has therefore created additional ten dedicated parking zones to accommodate the increased demand. The new additional parking areas include runway, taxiway, logistic apron and various other aprons.

To design or plan the additional parking positions, airport operators should take into account the following considerations:

- The additional position should be created in a way that it can be returned to their original purpose when needed;

- Parking positions of aircraft should allow their regular maintenance;

- The maintenance staff should have an easy and unrestricted access to aircraft in order to perform their duties. 


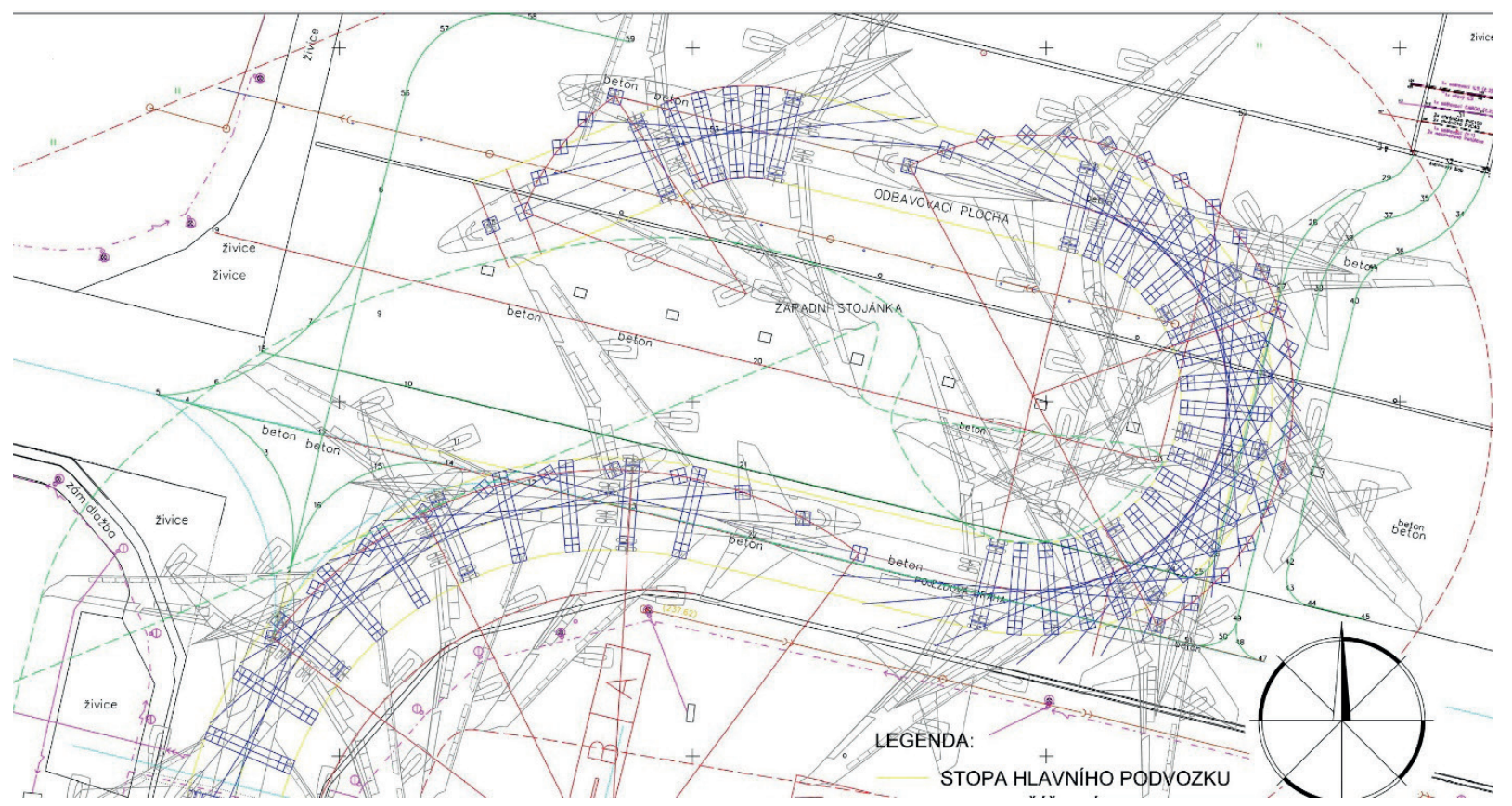

Figure 2 Visualization of B-747-400 maneuvering at Brno-Turany airport; author: Kazda, A.

An overflow parking is happening at most of airports around the world as an impact of COVID-19 pandemic. The FAA released national Part 139 CertAlert as an solution for an airport to handle the parking situation [17]. Le Bris states that it is a good practice to establish a parking plan and a procedure for temporary parking of overflow aircraft [8]. It should be prepared collaboratively by a workgroup or committee made of representatives of stakeholders potentially involved with such situations and should include airport operator, Rescue and Fire Fighting (RFF), Air Traffic Control (ATC), aircraft operators, ground handling service providers, fixed base operators, maintenance, repair and overhaul (MRO), etc. The plan should be scalable i.e. adaptable to different numbers and types of aircraft to pave the way for a timely and adequate response for the next time if the airport faces overflow of aircraft. This effort should consider and balance the needs of stakeholders, explore the short-term and long-term parking options and document the rationales behind the choices made. The plan and procedure should be regularly updated based on lessons learned and evolution of the airport conditions.

The plan should ideally be drawn using CAD applications (see Figure 2). This would facilitate the discussion with stakeholders, enhance the identification of potential geometric, safety issues and provide the teams in the field with an accurate depiction of the parking plan. This plan must feature support to position each aircraft. This can be the location of the nose and main gears. This assistance should be consistent with the means available in the field. For instance, if the GPS receivers or other surveying tools are not available to the crews, visual aids (e.g. number or identification number of concrete pavement slab) are recommended to supplement the geo referencing. Temporary markings can be provided as well.

Below are presented considerations recommended by the FAA [17] that should be applied when overflow of temporarily parking of aircraft at an airport is happening due to overcapacity during the COVID-19 emergency. This list should be considered as a minimum list of considerations and not as a complete list. Safety to the public and aircraft operations should remain the highest priority:

- Create an aircraft parking plan committee (airport operators are encouraged to work together as a committee with members of airlines and other related stakeholders).

- Document the aircraft parking plan considerations.

- Coordination of the plan (coordinate the plan for temporary parking of overflow aircraft at the airport with all the airport users as appropriate).

\section{Temporary aircraft parking risk assessment}

The airport operator is responsible for the rules and procedures that safeguard movements of aircraft on stands or apron and for dissemination of information to airline company operators. In line with the ACI airside safety book [20], it is the responsibility of airport operators to conduct a risk assessment to develop an objective of the risk associated with a specific activity. The risk assessments should be conducted for each task to be carried out by staff and can be carried out on a higher level of the operational business for example, prioritize the non-standard parking position. At the end, the risk assessment results could give airport operator an option while activating the nonstandard parking positions.

It is critical to assess the safety impact of overflow aircraft parking on infrastructure, obstacle limitation surfaces and operations and take the adequate measures to mitigate the risks, including the collision risks. It is also 
recommend by ACI World in their bulletin that the airport operators adjust to the specific conditions depending on their airports by creating safety risk assessment template [18]. The template could show a particular assessment such as hazards, consequences, the risk control rating, mitigation actions and new control for the specific risk events.

It is understood that most of the airport operators are facing the same challenge of finding new appropriate location for the aircraft to handle demand from the airlines as an impact of COVID-19 pandemic. According to ACI on their bulletin [18], this situation may lead to risks to the airport infrastructure and safety including:

- Damage from the use of pavement in a way not originally intended;

- $\quad$ Aircraft damage especially the risk of collision during the parking manoeuvres with minimum clearances;

- Runway or taxiway incursions;

- Issues around aircraft access and availability.

Most importantly, the parking plan and procedure must put safety first. Performing a safety risk assessment is necessary [21]. An airport must be able to continue operations safely. Closing part of the airport for storing aircraft means that a new taxiway layout is being created. This new, temporary layout must be able to accommodate the throughput and address the usual safety concerns including, but not limited to, runway incursions, NAVAIDS integrity and pilot deviations.

In addition, the line of sight from the tower to the active parts of the movement area must not be obstructed. Pilots need to be made aware of the runways and taxiways closed for parking aircraft. Specific Notices to Airmen (NOTAMs) shall be issued for raising situational awareness. In return, pilots shall report any issues such as the deviation or inaccuracy of the Instrument Landing System (ILS) signals or reflections lights which may cause confusion.

Adequate markings and signage should be provided as needed. Even if aircraft are parked on movement area pavements designed for regular use of aircraft, the positioning of the aircraft for the long-term parking may compromise safety. For instance, the tail of an aircraft parked diagonally on a taxiway might infringe runway protection surfaces or disturb the ILS signal while they are perfectly fine when an aircraft is aligned on the centerline.

The various safety areas and surfaces preventing safety issues and that protect flight operations shall be verified before parking aircraft. This is the reason why the FAA requests submittal of an FAA 7460 form if there is any potential impact on these surfaces in order to confirm potential hazard issues. If temporary engine run-up spots are provided, jet blast shall be carefully considered as well.

\section{$5 \quad$ Pavement loading characteristics}

During this time airports are bounded with limited parking capacity and considering other areas among them, as well with flexible pavements, to allocate the aircraft. Static loads from aircraft over a prolonged period may result in pavement deterioration, in particular in the case of flexible - asphalt pavements. Today aircraft operators and airports are facing medium to long-term aircraft storage issues. As aprons and parking areas are not designed for accommodating long term static loads prolonged aircraft storage on those areas can increase the risk of permanent deformations.

For pavement preservation while considering aircraft storage for long time, it is recommended to prefer areas with rigid pavements. Flexible type of pavements (asphalt) are not the best solution for parking areas for stands with high loadings. They are more sensitive than concrete paving to static loads and more sensitive to high temperatures due to bitumen's rheological properties, or more specifically, static loads from aircraft over a prolonged period, especially on flexible pavements, may result in pavement deterioration. In addition, while aircraft are parked, airlines need to conduct aircraft maintenance and any resulting fuel or oil spills could cause deterioration of asphalt pavement.

A pavement analysis should be carried out if the storage area is not designed to store aircraft for a long time considering as an overload on pavement. Parking and aprons, where aircraft operate at low to very low speed, are usually made of cement concrete pavements. The bearing strength of taxiways (moderate speed section) is greater than runways (except in some cases on runway thresholds), but lower than parking/aprons, which are purposely designed for accommodating static aircraft loads considering the movement [22]. The slower the speed, the lower the (complex) modulus of elasticity and the higher the shear strain at the bottom of the bituminous layer. Bituminous materials have a viscoelastic behavior and their modulus of elasticity depends on the temperature and the load frequency/speed (bituminous material rheological properties). Following the above consideration, it is implied that taxiways subjected to static aircraft loads are more sensitive to permanent deformation than those subjected to moderate or high-speed loadings.

In order to support airlines and airports with respect to aircraft storage for a long term, Airbus has produced a document for pavement and asset preservation that is supported by ACI. Furthermore, the document defines the best practices for aircraft storage on taxiways and runways. The main consideration for airlines and airports, while planning the long-term aircraft storage can be found on Airbus Consulting Services - Recommendations for pavement (storage area) preservation document [23].

As stated by the ACI in their advisory bulletin for mitigating the risk created by overflow aircraft parking, it is important to assess pavement strength to accommodate the loads and to check Aircraft Classification Number (ACN) and Pavement Classification Number (PCN) compatibility [18]. Technical analysis should be carried out before overloading pavements by more than $10 \%$ relative to reported pavement strength.

In addition, in the case that overloading cannot be avoided by the airport operator due to any reason (aircraft traffic/aircraft parking), according to advisory circular 


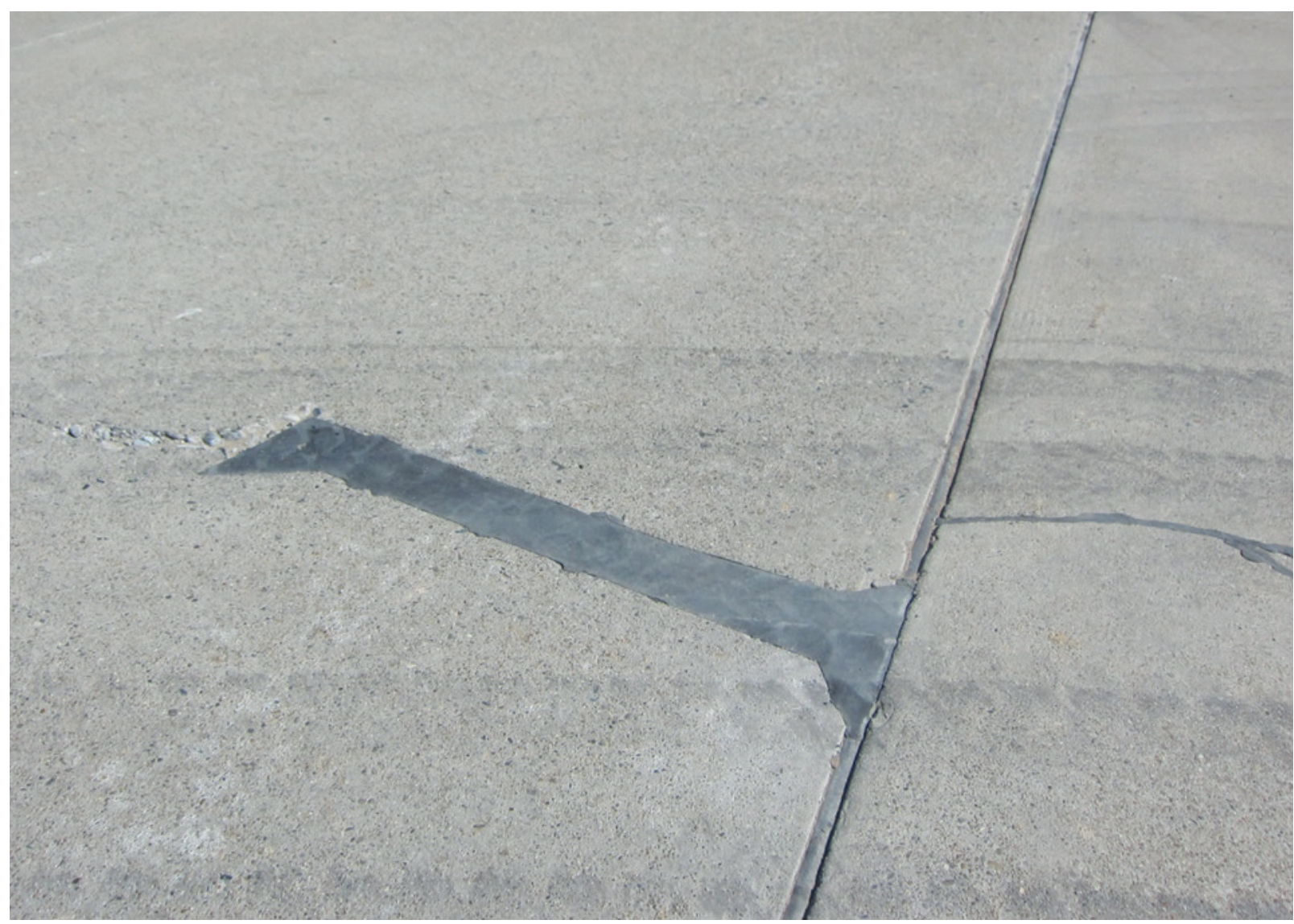

Figure 3 Intersecting cracks, cement concrete pavement slabs; author: Kazda, A.

published by FAA No:150/5335-5B [24], the airport authority has three options when making a pavement strength rating selection:

1. Let the PCN remains as derived from the technical evaluation method, but assess the pavement load/ overload with respect to local specifics, such as planned repairs or reconstructions. Experience with operation of a particular type of aircraft in a specific traffic mix can also have an impact on decision to operate with the ACNs that exceed the published PCN or at a reduced weight not to exceed the PCN.

2. Provide for an increased PCN by either adding an overlay or by reconstructing to accommodate aircraft with the higher ACNs.

Adjust the PCN upward to that of the aircraft with the highest ACN, but recognize the need to expect possible severe maintenance. This will result in earlier than planned reconstruction or overlay due to reduced pavement life.

3. The pavement load also depends on the tire pressure, which affects the size of the contact area between the tire and the pavement [22]. While planning aircraft storage for a long period, aircraft should be made as light as possible by unloading anything that can be appropriately and safely removed without jeopardizing its resistance to the wind. The load may be distributed over a larger contact area by deflating tires, but not less than recommended by the manufacturer.

In addition, as stated by Goodyear Aviation, one of the aircraft tire manufacturer in their published document, it is important to monitor the tire pressure at the prescribed values during the aircraft parking [25]. Tire pressures should always be checked when tires are cool, with the tire being at ambient temperatures. A tire/wheel assembly can lose as much as five percent of the inflation pressure in a 24-hour period and still be considered normal. This means that tire pressures change on a daily basis.

For instance, Qantas airlines maintenance team has put tire maintenance as one of their maintenance schedule during this massive grounding plan. The maintenance team ensures that aircraft have their wheels rotated-by being towed on tarmac or jacked up into the air to be rolled to ensure to perform tire maintenance as stated by Bloomberg [26].

\section{Pavement maintenance}

As stated by ACI, in their published bulletin pavement condition should be inspected regularly to monitor potential pavement deterioration [18]. When inspecting the pavement, deterioration that should be documented and include, but are not limited to:

- Depressions on flexible pavements under wheels;

- Ripples and bumps;

- Puncturing in case of inadequate pavement design;

- Damage from fluid leakage (in those areas, protection should be provided by a solvent-resistant surface). In addition to the above, Federal Aviation 
Administration (FAA) published in their advisory circular No 150/5380-6C that the airport authority is advised to conduct Pavement Management Program (PMP), which is an effective maintenance and repair system [27]. In addition, it is a systematic and consistent procedure for scheduling maintenance and rehabilitation based on maximizing benefits and minimizing costs. It is also explained that the primary component of any PMP is the ability to track a pavement's deterioration and determine the cause of the deterioration condition.

Pavements could deteriorate quickly if they are subjected to aircraft loadings that exceed their structural design strength. There are many formations of pavement deterioration according to the type, extent and severity conditions, as cited in filed guide report of Airport Cooperative Research Program (ACRP) [28]. Among them, one is intersecting cracks (see Figure 3) that break a slab into four or more pieces due to overloading, inadequate support, or both. Furthermore, pavement deterioration signs and probable cause are defined in pavement evaluation and rating document as per ICAO [29].

\section{Airport - airlines cooperation and coordination}

It is recommended that airports establish an aircraft parking committee that will review the temporary aircraft parking plan when necessary. All the relevant stakeholders should be represented in that committee. For proposed temporary parking of aircraft on aprons and taxiways airport operators are encouraged to work collectively as a committee with airline representatives, aircraft owners and fixed base operators, the air navigation services provider, rescue and firefighting corps, airport security team, airport safety team including airside safety and standards and airport schedulers [30].

The range of problems to be discussed within the aircraft parking committee could be wide. As explained by Laubrock [31], there are many other tasks and optimization potentials with respect to aircraft stands and gates. In particular, all the kinds of airports need an-effective IT solution, which could be customized depending on the airport stakeholder requirements [32]. For this, a collaboration is required between an airport operator, aircraft parking committee and IT team in order to plan a realistic operational plan and predictions [33] for proactive stand management, stand and gate capacity analysis, seasonal planning, airside capacity estimation, validation of airside planning, demand-capacity balancing, what-if - scenario testing and operational ad-hoc allocation [34].

\section{$8 \quad$ Aircraft grounding}

A remote parking plan should address the needs of different stakeholders. Aircraft operators have several needs and constraints that are specific to their aircraft storage strategy and should be discussed with them.
A parked aircraft is not just a dead weight that can be left for days without attention. It is a living piece of aviation engineering that is subject to strict airworthiness criteria. Systems and engines shall be turned on regularly otherwise a longer process will be required to return the aircraft to commercial operations. Aircraft hardware and software systems need care and attention. Manufacturers should establish extensive procedures in the Aircraft Maintenance Manuals (AMM) to preserve their airworthiness during the short and long-term parking. Procedures exist for servicing and protecting the aircraft parked for different periods. Consequently, maintenance teams should have access to the aircraft as far as practicable without an escort.

Some service roads might be restricted to specific airfield driver's license or might be closed by gates. Some roads might not have the adequate bearing strength for supporting all the vehicles used for aircraft servicing. For the same purpose of providing access an aircraft might be offset instead of centered on the taxiway to leave a side corridor for low-clearance vehicles.

The COVID-19 pandemic has put airlines on the edge of their business. Airlines do not have much choice except to reduce their service and park their aircraft for a long time or store them. As pointed out in [35], Brussels Airlines, for example, had to reduce their scheduled services due to COVID-19 and ground a large part of their fleet.

To provide support in this situation, Airframer, an aircraft manufacturing company, has developed dedicated instructions for storing the aircraft in a safe manner. Airframer states that is it important for the airlines to follow the instruction precisely so that 'they can easily and efficiently bring the aircraft back to normal operations'. At the same time, this will reduce the risk of additional work and costs when the aircraft is put back into service [36].

In the current situation, Brussels Airlines, for example, needs to spend about 400 man-hours to store an Airbus A330. This time is spent mainly to protect the aircraft to keep it clean and protected, such as by taping windows to avoid direct sunlight which could damage the cabin interior, covering the seats to keep them clean also covering the engines and landing gear to avoid any debris while restoring.

In addition to storing an aircraft, airlines say that aircraft cannot be left parked for a long period of time. Within the daily and weekly routine checks the maintenance staff has to slightly turn the aircraft wheels to avoid deformation due to the long-term load of the aircraft.

\section{$9 \quad$ Aircraft maintenance}

Another important issue for an airline to consider when grounding an aircraft is the responsibility to maintain the aircraft performance in accordance with the rules and regulation of the aviation authority. In addition to that, for an aircraft that is still on lease it is a mandatory requirement from the lessor to the lessee (airline) to maintain and conduct the maintenance of the aircraft until 
the termination of the lease. This requirement has the objective to maintain a valid certificate of airworthiness for aircraft at all time. Moreover, for an airline that is having a leased aircraft it is requested by the lessor to have various insurances to cover any kind of risks such as loss, damage and destruction of an aircraft, which could occur when aircraft is grounded for a long period. Realizing such kind of risks, instead of keeping the aircraft on ground and having difficulty to pay the lease, according to authors of [36], some airlines prefer to return the aircraft to the lessor or, if they own the aircraft, sell it and lease the aircraft back to obtain financial resources.

The procedure to store aircraft is commonly highlighted in aircraft manuals and the maintenance programmes. Additionally, each civil aviation regulatory authority has a set of standards that an airline operator has to follow. Parking an aircraft is usually covered with a section dedicated to parking, storage and return to service. As explained by Pandey [37], there are few procedures that an airline should follow before the aircraft is put into storage such as:

- Fuel and oil-levels are recorded and adjusted as required. The key risk that has to be guarded against is contamination of fuel in the wing tanks and ensuring adequate oil levels to guard against parts drying out. Some companies also add an element to fuel tanks called Biobor to keep microbial growth in the tanks at bay. As far as the airframe is concerned, visual inspections are carried out with all the possible inlets being carefully covered.

- Depending on weather conditions, landing gear and windows may have to be covered.

- Hydraulics, flaps, slats and auxiliary power unit (APU) may have to be periodically tested to ensure that the lubrication is adequate.

- Avionics may also be powered on to ensure these are in working condition.

There is always a risk for an aircraft when it is parked for a long period. Tsai from Boeing [38], clearly mentions that aircraft parking creates a risk that the aircraft may not be properly protected and may not be properly restored when they resume normal operations. As each aircraft has a different system of software and hardware means, the airlines need to pay more and more attention to protect and restore the aircraft after parking.

When the aircraft is parked, airlines need to have a scheduled maintenance in place to avoid more damage to the aircraft. It is also important to pay attention to verify the aircraft airworthiness such as aircraft configuration and operational status of aircraft system. Most of the airline MROs already noticed that any aircraft being restored to normal service after a long period of parking time would need an extra attention [39].

It is necessary to establish clear procedures and restrictions for aircraft access for fueling, cleaning and maintenance, including the engine runs; specify when access is needed day or night and decide who has the access. Measures should also be introduced to maintain the security of parked aircraft. Necessary equipment such as chocks, cones and tie-downs should be allocated and procedures determined, as well as using a clear identification or reference for each temporary parking position. It is also desirable to provide portable lighting for remote areas that are having limitation for lighting.

Inside the aircraft, certain systems must be deactivated. All windows and doors should be covered (ideally), as well as the landing gear and tires. This is towards protecting them from the elements. All the carts should be emptied out; seats covered with plastic sheets if required and in certain cases some equipment should be removed from the aircraft. The inside cabin should also be aired to ensure minimal moisture and mitigate any impact of heat. All of this is also critical towards ensuring that the aircraft, once ready to fly, can be put back to use in the fastest possible time.

For airlines, as an advice from author of [40], it is a good practice to apply protection to the aircraft exterior and interior before parking, as it will ensure that the paint remains undamaged. In addition, it is a good idea to regularly air out the cabin of the airplane by opening all possible access points including the baggage/cargo compartment as it is better to getting air moving through the cabin as much as possible.

Etihad Airways chose another approach to aircraft maintenance during the COVID-19 pandemic. As mentioned by Guillot [41], the national carrier of the United Arab Emirates (UAE) is reacting in different way by launching the most extensive maintenance program in the history of the airline. They took this initiative as an effect of COVID19 that forced them to ground most of their fleet at Abu Dhabi International Airport. Etihad takes advantage of the situations to clean, refresh, repair and if required, to improve aircraft cabins before resuming the service. This includes conducting an update to the In-flight Entertainment (IFE). For the cabin interior part the airlines did massive cleaning and laundry such as the leather upholstery that belong to the first and business class seats. The aim of all of these actions is to keep the aircraft ready when the operations resume.

\section{Engine maintenance}

More than $40 \%$ of Direct Operating Cost for a typical wide body aircraft can be directly attributed to engine performance, design and reliability [42]. Engines are the most expensive item and, unfortunately, are the most variable and sensitive to operation standards. The only way how one can predict maintenance actions or to adjust to industry average, it is to properly reflect on all the aspects of operations [43]. In addition to the aircraft storage, engine storage has its own set of requirements. Lessors' permit airlines to enter into engine maintenance costs per flight hour, power by the hour (PBTH), fleet management programs (FMPs) or similar agreements with engine manufacturers or any other engine maintenance 


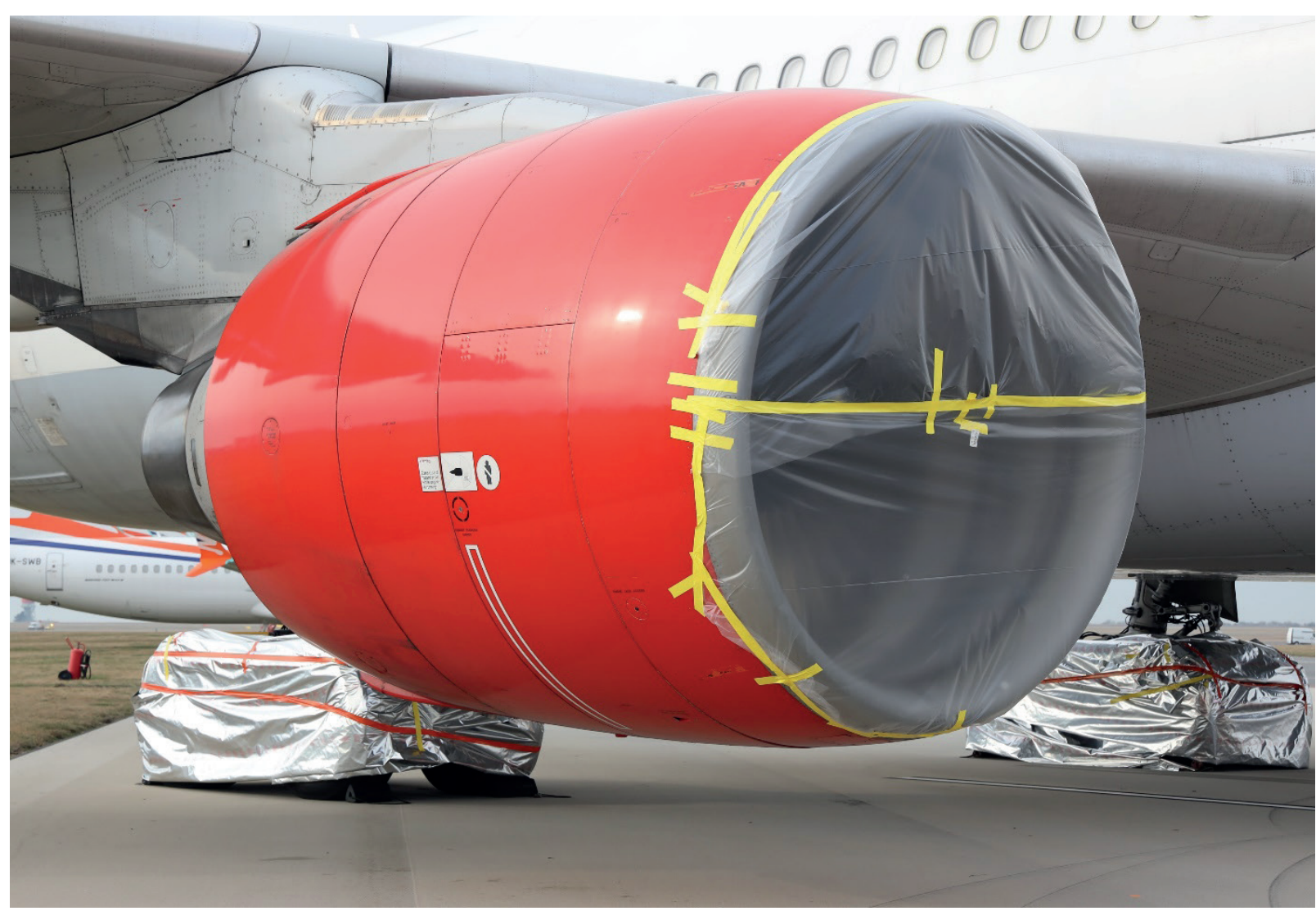

Figure 4 Engine inlets properly sealed and wheels thoroughly covered; author: Melus, M.

facility, provided the terms of such an agreement are fully in compliance with requirements in the lease agreement. This often helps airlines to reduce significantly maintenance costs without compromising on the quality of the work.

Currently, most of airlines MRO department are working continuously for maintaining the fleet of grounded aircraft. In terms of engine maintenance, new processes and procedures had to be set up that includes the running engines, powering up the aircraft, covering the sensors to protect from sand and dust as well as checking flight control instruments. Engineers, duly trained and certified by the relevant authorities among other things, have to ensure that the engine parts and bearings are properly lubricated, all inlets covered and sealed (see Figure 4). Each aircraft comes with a set of engine covers and thus one sees aircraft parked with engines covered. Aircraft engines also need to be run at regular intervals. As an example, when the Boeing 737Max issue surfaced and aircraft were grounded maintenance programs required that engineers power up the engines once a week to vaporize any moisture in the oil and fuel systems. Running up the engines also allows for circulation and fuel change in the system to prevent degradation of seals and rubber parts in the pipes and fuel pumps [44].

Large fleet of parked aircraft therefore requires availability of technical staff. For example, 650 parked aircraft represent 1300 engines with 14 variants across 5 manufacturers, which will have to be powered and run at idle for a specific amount of time, depending on manufacturer recommendations.
Siebenmark mentions that engines require specific treatment such as the use of engine cover [40]. Desiccants mounted in the inlet and outlet of the engine as well as humidity indicators, should be used in the covered engine to ensure that the humidity does not exceed the limits. The other important thing is to conduct regular scheduled inspections while the aircraft remains in long-term storage.

\section{Aircraft return to service}

Once the go-ahead is given for a return to service, airlines cannot simply take the aircraft and return it to flight operations. Extensive documentation and checks should again be carried out. The primary goal of aviation is safety and ensuring continued airworthiness. This also poses a regulatory challenge since a regulator is simply not staffed to oversee such a large volume of aircraft. How the return to service will be managed remains a matter of much debate within aviation circles

An advice from one of the aircraft manufacture technical person [38] is that the operational status of an airplane in service is significantly different from an aircraft after returning from maintenance or parking for more than one day. If an operational testing is required after a long period of grounding of an aircraft, then the maintenance measures must be carried out. In addition, recommendations from each person involved in returning the aircraft to service are crucial for the airlines to maintain the safety of the aircraft. 


\section{Airport returning to normal}

Airport operators should consider re-certification of runway and taxiway pavements used to park aircraft during the COVID-19 pandemic before resuming operations. If some pavement distresses have not been identified at the return to normal service of the area, the risk will be transferred to aircraft and in those cases required repairs would affect operations. It is not only the airport operators, many aviation authority and regulator are not able to perform their standard administration of various licenses as their operations have also been impacted by the COVID-19 outbreak.

To handle this, ICAO in their press release [45] established a system called COVID-19 Contingency Related Differences (CCRD) to support all the states to be able to record any kind of differences related to their standard policies. With this action, ICAO will be able to ensure the safe continuity of flights between countries in a good manner and to have this documented once operations back to normal.

\section{Conclusion and further research}

The COVID-19 adverse impact on the whole aviation industry has forced airlines and airports to significantly reduce their operations according to the depleted travel demand and restrictions imposed by the states. This situation turned challenging for airport operators when the airlines are forced to store their fleet for a long term. In order to facilitate airline requirements for storing aircraft, airport operators had to prepare plans in collaboration with key stakeholders to ensure that all the essential matters are addressed, while maintaining safety of operations.

In order to respond to the situation, both airline and airport operators along with aircraft manufactures, have taken various measures from accommodating grounded aircraft on specific parking slots to create a heavy maintenance schedule to keep aircraft safe and airworthy by adhering to standards and requirements. Furthermore, appropriate precautions need to be considered to ensure serviceability as aircraft and related equipment are static for a long period. Storing aircraft for a long time could become a massive problem for airlines if they could not manage and maintain it appropriately.

In addition to above, the airline maintenance team has a key role to play in in order to maintain grounded aircraft. They need to have a precise schedule including the preparation when aircraft needs to fly again. The engine, cabin interior and exterior, avionics, wheels, are the critical assets that airlines need to pay more attention to. For this, as the best practice the airlines can always refer to Aircraft Maintenance Manual provided by manufacturing company.

Similarly, airport operator needs to draw more attention to ensure pavement condition is safe, secure for aircraft performance and to accommodate airlines line maintenance team to conduct necessary scheduled maintenance activity on grounded aircraft. In addition, the airport operator shall ensure access to current and new parking stands is available and maintained to avoid any delay that can affect aircraft performance.

Ultimately, the airports and airlines are suggested to always ensure safety as a top priority as advice by ICAO, ACI, FAA, EASA and the aircraft manufacturing companies. All the key stakeholders need to ensure and understand the current operational environment as vital for the long-term sustainability of aviation industry.

The problem of aircraft long-term parking is associated with other issues as, for example, airport pavements longterm static loadings, which may be a subject of further research.

\section{Acknowledgment}

This research was supported under the project of Operational Programme Integrated Infrastructure: Research and development of contactless methods for obtaining geospatial data for forest monitoring to improve forest management and enhance forest protection, ITMS code 313011V465. The project is co-funding by European Regional Development Fund.

\section{References}

[1] KINGSLEY-JONES, M. Mixed fortunes globally as active fleet drops towards 7,000 aircraft [online] [accessed 2020-0420]. 2020. Available from: https://www.flightglobal.com/fleets/mixed-fortunes-globally-as-active-fleet-drops-towards7000-aircraft/137893.article

[2] ICAO. Annex 14, Aerodromes. Vol. I. Aerodrome Design and Operations. 8. ed. Montreal: International Civil Aviation Organisation, 2018.

[3] EASA. Easy Access Rules for Aerodromes [online] [accessed 2019-05-30]. 2019. Available from: https://www.easa. europa.eu/newsroom-and-events/news/easy-access-rules-aerodromes-updated

[4] FAA. Airport Design and Engineering Standards. AC 150/5300-13A, Apron, (Appendix 5). Washington, 2012.

[5] ICAO. Aerodrome Design Manual. Part 2. Taxiways, Aprons and Holding Bays. Montreal: International Civil Aviation Organization, 2005.

[6] FAA. Temporary Parking of Overflow Aircraft [online] [accessed 2020-04-01]. 2020. Available from: https://www.faa.gov/ airports/airport_safety/certalerts/media/part-139-cert-alert-20-02-COVID-19-temporary-aircraft-parking.pdf 
[7] FAA. Safety Alert for Operators [online] [Accessed 2020-05-31]. 2020. Available from: https://www.faa.gov/other_visit/ aviation_industry/airline_operators/airline_safety/safo/all_safos/media/2020/SAFO20005.pdf

[8] LE BRIS, G. Best practices on the temporary parking of overflow aircraft [online] [accessed 2020-04-18]. 2020. Available from: https://www.wsp.com/en-NZ/insights/2020-temporary-parking-of-overflow-aircraft

[9] Boeing. Boeing Commercial Airplanes - Orders and Deliveries - 737 Model Summary [online] [accessed 2020-07-07] 2018. Available from: http://active.boeing.com/commercial/orders/displaystandardreport.cfm?cboCurrentModel=737 \&optReportType=AllModels\&cboAllModel=737\&ViewReportF=View+Report

[10] HEMMERDINGER, J. Boeing to halt 737 production in January [online] [accessed 2020-07-07]. 2019. Available from: https://www.flightglobal.com/programmes/boeing-to-halt-737-production-in-january/135807.article

[11] MOLNAR, Z., MILDEOVA, S., BRIXI, R., KALINA, J. Advanced methods of scientific work / Pokrocile metody vedecke prace (in Czech). Praha: Edition Profess Consulting, s.r.o., 2012. ISBN 978-80-7259-064-3.

[12] SERRANO, F., KAZDA, A. The future of airport post COVID-19. Journal of Air Transport Management [online]. 2020, 89, 101900. ISSN 0969-6997. Available from: https://doi.org/10.1016/j.jairtraman.2020.101900

[13] Stanford Encyclopedia of Philosophy. The problem of induction [online]. 2018. Available from: https://plato.stanford. edu/entries/induction-problem

[14] ANILKUMAR, P. D. Historical method [online] [accessed 2020-08-24]. 2014. Available from: https://www.academia. edu/22583546/Historical_Method_of_Research

[15] KAZDA, A. Business operation, selected parts / Obchodna prevadzkova cinnost, vybrane state (in Slovak) - Business operation, selected parts. Bratislava: Alfa, 1985. Order N³430/84.

[16] US.DOT. Advisory Circular-Operational Safety on Airport during Construction [online] [Accessed 2020-05-09]. 2011. Available from: https://www.faa.gov/documentlibrary/media/advisory_circular/150_5370_2f.pdf

[17] FAA. FAA National Part 139 CertAlert No. 20-02 [online] [accessed 2020-03-28]. 2020. Available from: https://www.faa. gov/airports/airport_safety/certalerts/media/part-139-cert-alert-20-02-COVID-19-temporary-aircraft-parking.pdf

[18] ACI. ACI Advisory bulletin-mitigating the risk created by overflow aircraft parking [online] [accessed 2020-05-30]. 2020. Available from: https://aci.aero/wp-content/uploads/2020/04/200423-Airfield-Parking-Advisory-Bulletin-FINAL_001.pdf

[19] CREEDY, S. Parking planes in the time of COVID-19. The Airport Proffesional [online] [accessed 2020-04-11]. 2020. Available from: https://airportprofessional.asn.au/major-airports/parking-planes-in-the-time-of-covid-19

[20] ACI. Airside Safety Handbook. 4. ed. [online] [accessed 2020-05-21]. 2010. Available from: https://www.skybrary.aero/ bookshelf/books/3171.pdf

[21] GALIERIKOVA, A., MATERNA, M., SOSEDOVA, J. Analysis of risks in aviation. In: International Conference Transport Means: proceedings. 2018. Vol. 22. p. 1427-1431.

[22] KAZDA, A. CAVES, R. E. Airport design and operation. 3rd ed. Bingley: Emerald Group Publishing Limited, 2015. ISBN 978-1-78441-870-0.

[23] Airbus. Airbus Consulting Services: Recommendations for pavement (storage area) preservation [online] [accessed 2020-05-30]. 2020. Available from: https://services.airbus.com/en/newsroom/stories/2020/04/covid-19-aircraft-long-termstorage-asset-preservation.html

[24] US.DOT-FAA. Standardized method of reporting airport pavement strength - PCN [online] [accessed 2020-05-30]. 2011. Available from: https://www.faa.gov/documentLibrary/media/Advisory_Circular/150_5335_5B.pdf

[25] Goodyear Aviation. Aircraft tire care and maintenance [online] [accessed 2020-05-30]. 2004. Available from: https:// www.spilve.lv/library/procedures/Aircraft\%20Tire\%20Care\%20and\%20Maintenance.pdf

[26] Bloomberg. Here's what you do with two-thirds of the world's jets when they can't fly [online] [Accessed 2020-04-24]. 2020. Available from: https://www.bloombergquint.com/business/coronavirus-travel-what-happens-to-planes-groundedby-covid-19

[27] US.DOT - FAA. Guidelines and procedures for maintenance of airport pavements [online] [accessed 2020-05-30]. 2014. Available from: https://www.faa.gov/documentlibrary/media/advisory_circular/150-5380-6c.pdf

[28] ACRP. Field guide for the airport pavement maintenance recommendation tool for ACRP report 159 [online] [accessed 2020-05-30]. 2020. Available from: http://onlinepubs.trb.org/onlinepubs/acrp/acrp_rpt_159_FieldGuide.pdf

[29] The Louis Berger Group. Pavement evaluation \& rating [online] [accessed 2020-05-31]. 2012. Available from: https:// www.icao.int/SAM/Documents/2012/IX.ALACPA/2-final\%2009-08-2012\%20Topic\%202\%20Airfield\%20Pavement\%20 Surface\%20Evaluation\%20and\%20Rating.pdf

[30] BADANIK, B. Airlines' point of view as a new approach to measuring quality of service at airports. In: 26th Congress of International Council of the Aeronautical Sciences ICAS 2008: proceedings. 2008.

[31] LAUBROCK, M. New approach for scenario based stand \& gate allocation and planning - airport research center. Airport Research Center [online] [accessed 2020-05-30]. 2020. Available from: https://arc.de/article-new-approach-forscenario-based-stand-allocation-and-planning

[32] NOVAK SEDLACKOVA, A., NOVAK, A. Simulation at the Bratislava airport after application of directive 2009/12/EC on airport charges. Transport and Telecommunication. 2010, 11(2), p. 50-59. ISSN 1407-6160, eISSN $\quad$ 1407-6179. 
[33] LAZAR, T., NOVAK SEDLACKOVA, A., BREDA, R. Regression in personal air transport of passengers evolution at selected airport time series method. Nase More [online]. 2015, 62(3), p. 228-232. ISSN 0469-6255, eISSN $1848-6320$. Available from: https://doi.org/10.17818/NM/2015/SI26

[34] MATAS, M. NOVAK, A. Models of processes as components of air passenger flow model. Communications - Scientific Letters of the University of Zilina [online]. 2008, 10(2), p. 50-54. ISSN 1335-4205, eISSN 2585-7878. Available from: http://komunikacie.uniza.sk/index.php/communications/article/view/1045

[35] PROKOPOVIC, K. How do airlines prepare their fleet for hibernation? [online] [accessed 2020-04-21]. Available from: https://aviationvoice.com/how-do-airlines-prepare-their-fleet-for-hibernation-202004110139

[36] SPRINGTHORPE, R., BATCHELOR, D. COVID-19 and the practical implications for the global aviation industry [online] [accessed 2020-04-01]. 2020. Available from: https://www.nortonrosefulbright.com/de-de/wissen/publications/895cf5ba/ covid-19-and-the-practical-implications-for-the-global-aviation-industry

[37] PANDEY, S. Lockdown woes: storage and return to service of grounded aircraft [online] [accessed 2020-04-03]. 2020. Available from: https://sarinlaw.com/lockdown-woes-storage-and-return-to-service-of-grounded-aircraft

[38] TSAI, B. Boeing - airplane return to service after extended downtime [online] [Accessed 2020-05-30]. 2020. Available from: https://www.boeing.com/commercial/aeromagazine/aero_04/textonly/s02txt.html

[39] PAGE, R. What happens when an airplane is parked for too long [online] [accessed 2020-08-21]. 2020. Available from: https:/www.airspacetechnologies.com/blog/what-happens-when-an-airplane-is-parked-for-too-long

[40] SIEBENMARK, J. Parking an airplane? Here's what you need to know [online] [accessed 2020-04-18]. 2020. Available from: https://www.ainonline.com/aviation-news/business-aviation/2020-04-15/parking-airplane-heres-what-you-needknow

[41] GUILLOT, R. The largest maintenance programme in Etihad's history is underway. Le Journal da L'Aviation [online] [accessed 2020-05-03]. 2020. Available from: https://www.journal-aviation.com/en/news/44234-the-largest-maintenanceprogramme-in-etihad-s-history-is-underway

[42] KANG, M., OGAJI, S., PILIDIS, P., KONG, C. An approach to maintenace cost estimation for aircraft engines. In: ASME Turbo Expo 2008: Power for Land, Sea and Air: proceedings. Aircraft Engine; Ceramics; Coal, Biomass and Alternative Fuels; Manufacturing, Materials and Metallurgy; Microturbines and Small Turbomachinery. Vol. 1. 2008. ISBN 9780791843116, p. 71-79.

[43] BUGAJ, M., URMINSKY, T., ROSTAS, J., PECHO, P. Aircraft maintenance reserves - new approach to optimization. Transportation Research Procedia [online]. 2019, 43, p. 31-40. ISSN 2352-1465. Available from: https://doi.org/10.1016/j. trpro.2019.12.016

[44] PECHO, P., BUGAJ, M. Vibration fault detection of fuel pump using recurrence quantification analysis. Transportation Research Procedia [online]. 2018, 35, p. 287-294. ISSN 2352-1465. Available from: https://doi.org/10.1016/j. trpro.2018.12.009

[45] ICAO. COVID-19 contingency related differences (CCRD) [online] [accessed 2020-05-29]. 2020. Available from: https://www.icao.int/safety/COVID-19OPS/Pages/ccrd.aspx 


\section{List of abbreviations}

\begin{tabular}{|c|c|}
\hline abbreviation & meaning/phrase \\
\hline $\mathrm{ACN}$ & Aircraft Classification Number \\
\hline AMM & Aircraft Maintenance Manuals \\
\hline ACRP & Airport Cooperative Research Program \\
\hline $\mathrm{ACI}$ & Airports Council International \\
\hline ATC & Air Traffic Control \\
\hline APU & Auxiliary Power Unit \\
\hline CCRD & COVID -19 Contingency Related Differences \\
\hline EASA & European Union Aviation Safety Agency \\
\hline FAA & Federal Aviation Administration \\
\hline FMPs & Fleet Management Programs \\
\hline GPS & Global Positioning System \\
\hline IFE & In-flight Entertainment \\
\hline ILS & Instrument Landing System \\
\hline ICAO & International Civil Aviation Organization \\
\hline MRO & Maintenance, Repair and Overhaul \\
\hline NOTAM & Notices to Airmen \\
\hline $\mathrm{RFF}$ & Rescue and Fire Fighting \\
\hline RWY & Runway \\
\hline PCN & Pavement Classification Number \\
\hline PMP & Pavement Management Program \\
\hline PBTH & Power by the Hour \\
\hline SAFO & Safety Alert for Operators \\
\hline UAE & United Arab Emirates \\
\hline
\end{tabular}

